\title{
BANDA DE CISALHAMENTO ADIABÁTICO INDUZIDA POR ALTA TAXA DE DEFORMAÇÃO EM UM AÇO BALÍSTICO *
}

\author{
Suzane de Sant'ana Oliveira ${ }^{1}$ \\ Karollyne Gomes de Castro Monsores ${ }^{2}$ \\ Anderson Oliveira da Silva ${ }^{3}$ \\ Elson Renato Santos Souza 4 \\ Ricardo Pondé Weber ${ }^{5}$ \\ João Carlos Miguez Suarez $z^{6}$
}

\section{Resumo}

Este trabalho teve como objetivo estudar as possíveis transformações microestruturais ocorridas em um aço de alta dureza submetido a altas taxas de deformação induzida por impacto balístico de um projetil $7,62 \times 51 \mathrm{~mm}$ perfurante (Pf). Este aço, produzido por siderúrgicas nacionais, compõe o quadro de materiais nacionais usados como blindagens para proteção veicular. Após o ensaio balístico, a microestrutura do material "como recebido" e da região adjacente ao impacto, foi analisada por meio de microscopia eletrônica de varredura. Os resultados comprovaram o surgimento da microestrutura conhecida por banda de cisalhamento adiabático nos impactos que produziram perfuração, ou seja, penetração completa do projetil, de acordo com o critério da Marinha.

Palavras-chave:Aço de alta dureza; Ensaio balístico; Bandas de cisalhamento adiabático.

\section{ADIABATIC SHEAR BAND INDUCED BY HIGH RATE DEFORMATION IN A BALLITIC STEEL}

\section{Abstract}

The aim of this work was to study the possible microstructural transformations in a high hardness steel subjected to high rates of ballistic impact induced deformation of a projectile $7.62 \times 51 \mathrm{~mm}(\mathrm{AP})$. This steel, produced by national steelmakers, composes the table of national materials used as armors for vehicular protection. After the ballistic test, the microstructure of the material "as received" and the region adjacent to the impact was analyzed by scanning electron microscopy. The results confirmed the appearance of the microstructure known as the adiabatic shear band in the impacts that that provided drilling, that is to say, full penetration of the projectile, according to Navy criteria.

Keywords: High hardness armor steel; Ballistic test; Adiabatic shear band.

1 Tecnologia em Processos Metalúrgicos, Mestre, Doutoranda em Ciência dos Materiais, Seção de Engenharia Mecânica e de Materiais, Instituto Militar de Engenharia, Rio de Janeiro, RJ, Brasil.

2 Tecnologia de Polímeros, Mestre, Doutoranda em Ciência dos Materiais, Seção de Engenharia Mecânica e de Materiais Instituto Militar de Engenharia, Rio de Janeiro, Rio de Janeiro e Brasil.

$3 \quad$ Licenciatura em Química, Mestrando em Ciência dos Materiais, Seção de Engenharia Mecânica e de Materiais Instituto Militar de Engenharia, Rio de Janeiro, Rio de Janeiro e Brasil.

4 Engenharia de Materiais, Mestre, Engenheiro de Pesquisa e Desenvolvimento de Blindagens, Departamento de Ciência e Tecnologia, Exército Brasileiro, Rio de Janeiro, RJ, Brasil.

5 Engenharia Mecânica, Doutor, Professor do curso de Ciência dos Materiais, Seção de Engenharia Mecânica e de Materiais, Instituto Militar de Engenharia, Rio de Janeiro, RJ, Brasil.

6 Engenharia Industrial e de Metalurgia, Doutor em Ciência e Tecnologia dos Polímeros, Seção de Engenharia Mecânica e de Materiais, Instituto Militar de Engenharia, Rio de Janeiro, RJ, Brasil. 


\section{INTRODUÇÃO}

O estudo dos materiais têm tido um grande avanço em sua trajetória, especialmente nas últimas décadas. O que outrora era um pensamento, atualmente são projetos que necessitam tanto de materiais quanto de pessoas qualificadas para a sua concretização.

Tal qual a sociedade, a tecnologia passa por transformações e as proteções balísticas para diferentes níveis de ameaça acompanham tais transformações. Estas mudanças conceituais produziram novos materiais de baixa densidade e alta resistência balística, como polímeros e cerâmicos. Porém, em certas aplicações, tais como veículos militares, os aços ainda são os mais utilizados como material de blindagem devido ao seu baixo custo e flexibilidade de obter propriedades balísticas otimizadas por meio de tratamentos térmicos, tais como têmpera e revenido $[1,2]$.

Para possuir um bom desempenho balístico, uma blindagem metálica precisa ser resistente à penetração, ao estilhaçamento e ao choque. Por isso, tratamentos térmicos são realizados a fim de alcançar um equilíbrio entre dureza e tenacidade. $A$ função da dureza em um projeto balístico é a de quebrar a ponta do projetil, para diminuir o poder de penetração do mesmo, e a tenacidade a de absorver a energia cinética durante o impacto. Todavia, o excesso de dureza pode se tornar prejudicial $[1,3,4,5]$.

Baseado nos resultados balísticos pode-se definir o mecanismo que conduziu a falha, isto é, através da comparação do tipo de fratura do metal com a classificação das falhas tradicionais, é possível predizer se a falha ocorreu por falta ou excesso de dureza. Por exemplo, uma falha classificada como batoque ou "plugging" no material impactado, é considerada como resultado de uma fratura por cisalhamento, devido ao aumento da dureza do material $[6,7]$.

Em certos materiais, as análises por microscopia eletrônica de varredura da região fraturada por cisalhamento, após o impacto do projétil, podem apresentar uma falha dúctil denominada Banda de Cisalhamento Adiabático (BCA). Essas bandas surgem devido à baixa taxa de dissipação do calor para a vizinhança do impacto balístico quando comparada a alta taxa de aquecimento localizado nesta região, proveniente das altas taxas de deformações produzidas pelo projetil $[8,9,10,11]$.

Este trabalho teve como objetivo analisar a microestrutura de um aço de alta dureza, após o ensaio balístico com um projetil $7.62 \times 51 \mathrm{~mm}$ perfurante.

\section{MATERIAIS E MÉTODOS}

\subsection{Material}

O material estudado foi um aço de alta dureza (HHA - High Hardness Armor steel), desenvolvido por siderúrgicas nacionais, juntamente com o Exército Brasileiro (EB), de acordo com a norma MIL-DTL-46100E [12]. O aço HHA possui a seguinte composição química: 0,31\% C; $0,42 \% \mathrm{Mn} ; 0,57 \% \mathrm{Ni} ; 0,76 \% \mathrm{Cr} ; 0,30 \% \mathrm{Mo} ; 0,05 \%$ $\mathrm{Cu} ; 0,03 \%$ Ti e $0,009 \% \mathrm{P}+\mathrm{S}$.

A produção deste aço foi realizada em forno a arco voltaico, com refusão sob escória eletrocondutora (ESR), laminado em temperatura média de $1100^{\circ} \mathrm{C}$, temperado em aproximadamente $1000^{\circ} \mathrm{C}$ e revenido a $400^{\circ} \mathrm{C}$ [13]. 


\subsection{Ensaio balístico}

O ensaio balístico foi realizado em um alvo de $500 \mathrm{~mm}$ × $500 \mathrm{~mm}$ × $8 \mathrm{~mm}$ de espessura, posicionado a $15 \mathrm{~m}$ de distância do provete. A munição utilizada foi o projetil 7,62 $\mathrm{mm}$ perfurante, com massa nominal de 9,6 g e o impacto foi realizado a $0^{\circ}$ de obliqüidade em relação ao alvo. O dispositivo utilizado para a medição da velocidade de impacto foi a "barreira ótica", como apresentado na Figura 1 [4].

Os impactos foram classificados em penetração parcial (PP) e penetração completa (PC), de acordo com o critério da Marinha, que considera penetração completa aquela onde o projetil ultrapassa o alvo ou quando observa-se que mais de $50 \%$ do mesmo ultrapassou a face distal do alvo.

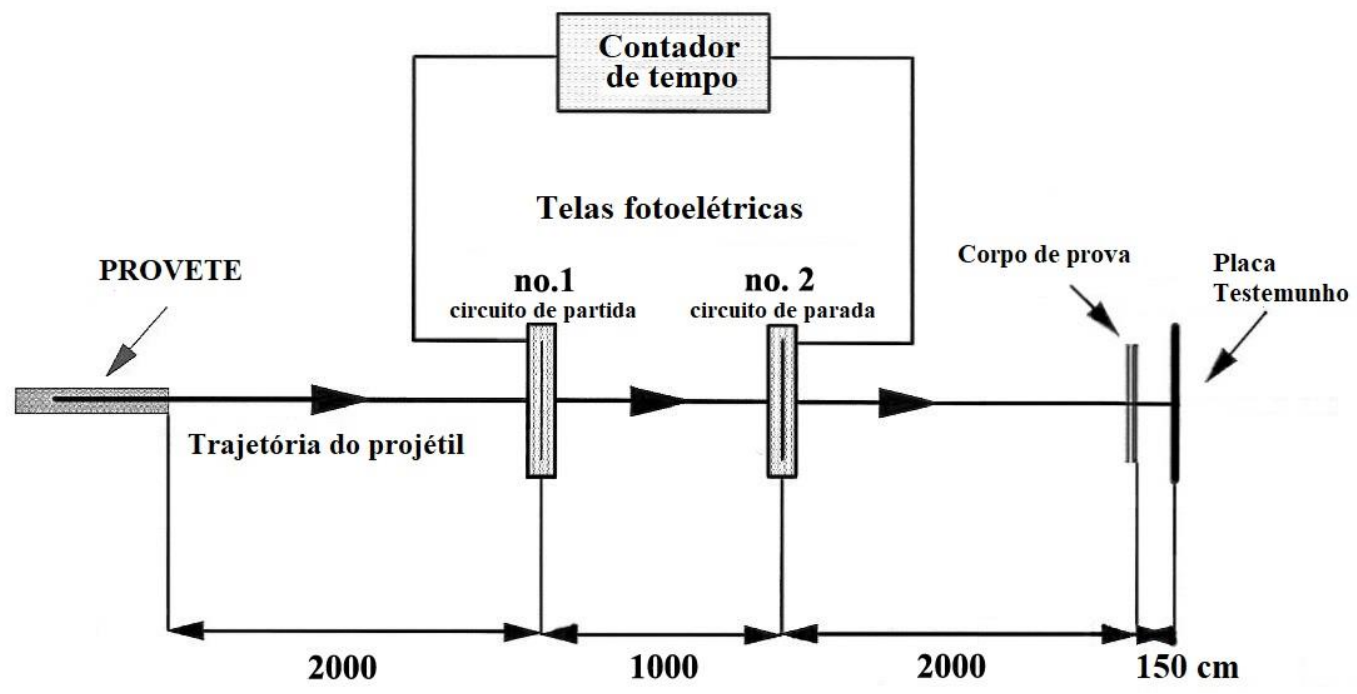

Figura 1. Esquema ilustrativo da barreira ótica

\subsection{Análise por microscopia eletrônica de varredura}

Após o ensaio balístico, uma região impactada foi escolhida e cortada pela técnica de jato d'água, para prevenir transformações térmicas no material estudado, obtendo-se uma amostra de $15 \times 15 \mathrm{~mm}$, que foi preparada metalograficamente, sendo atacada com Nital $2 \%$ e analisada por meio de microscopia eletrônica de varredura (MEV) para observar a microestrutura do material "como recebido" e da região adjacente ao impacto.

\section{RESULTADOS E DISCUSSÃO}

A Figura 2 apresenta a microestrutura martensítica revenida, oriunda do tratamento térmico de têmpera e revenido, antes do ensaio balístico, no aço estudado. 


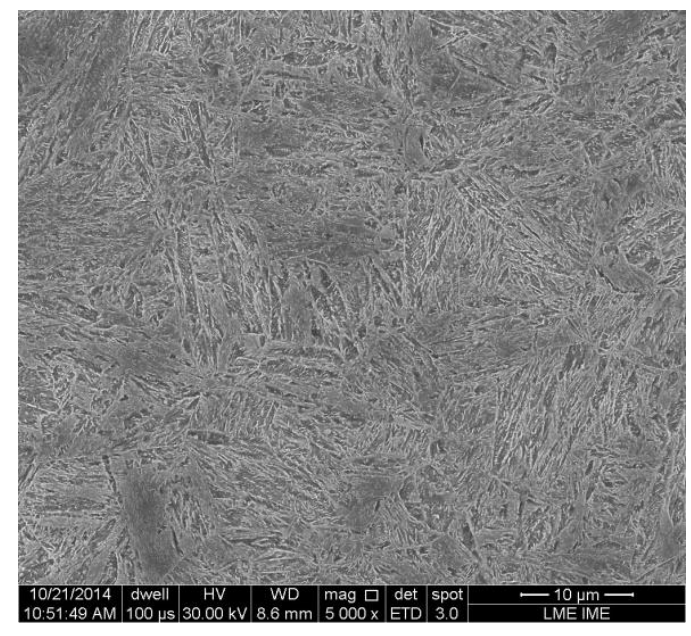

Figura 2. Fotomicrografia do aço HHA "como recebido", apresentando a microestrutura martensítica revenida, antes do ensaio balístico.

A Tabela 1 apresenta os resultados do ensaio balístico realizado na chapa do aço estudado. A Figura 3 mostra a vista da face frontal da chapa impactada. Dos 8 (oito) impactos realizados, apenas 5 foram considerados válidos de acordo com a norma NIJ 0108 [14]. Os impactos considerados válidos ocorreram em uma faixa de velocidade que variou entre $530 \mathrm{~m} / \mathrm{s}$ e $636 \mathrm{~m} / \mathrm{s}$.

Tabela 1. Condições do ensaio balístico.

\begin{tabular}{|l|c|c|c|c|c|}
\hline Material & Munição & Impacto & Energia (J) & $\begin{array}{c}\text { Projetil } \\
\text { V1 (m/s) }\end{array}$ & Resultado \\
\hline & & 1 & 1348 & $\mathbf{5 3 0}$ & PC \\
\cline { 3 - 6 } & & 2 & 1505 & $\mathbf{5 6 0}$ & PP \\
\hline \multirow{3}{*}{$\begin{array}{l}\text { Aço HHA } \\
\mathbf{8 , 0 0} \mathbf{~ m m}\end{array}$} & \multirow{2}{*}{7.62 Perf } & 3 & 1384 & $\mathbf{5 3 7}$ & PP \\
\cline { 3 - 6 } & & 4 & 1559 & $\mathbf{5 7 0}$ & PC \\
\cline { 3 - 6 } & & 5 & 1941 & $\mathbf{6 3 6}$ & PC \\
\hline
\end{tabular}

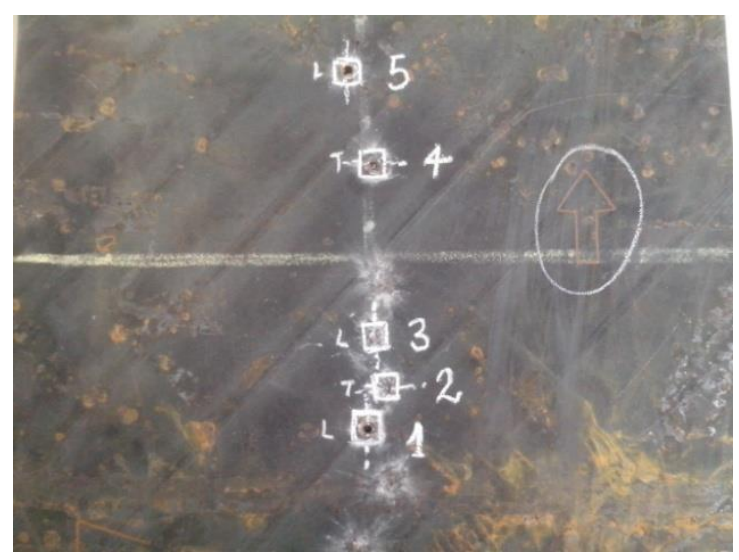

Figura 3. Chapa do aço HHA após o ensaio balístico com os 5 impactos considerados válidos. A seta indica a direção de laminação.

Segundo o critério da Marinha, três (3) penetrações completas (PC) e duas (2) parciais (PP) ocorreram no ensaio balístico. 
O impacto número 1 foi escolhido para a análise metalográfica a ser realizada no microscópio eletrônico de varredura (MEV).

Algumas regiões na amostra avaliada apresentaram uma microestrutura diferenciada, confirmada como banda de cisalhamento adiabático $[8,10,11]$.

A Figura 4 apresenta uma banda de cisalhamento adiabático envolvida pela microestrutura martensítica revenida do material "como recebido".

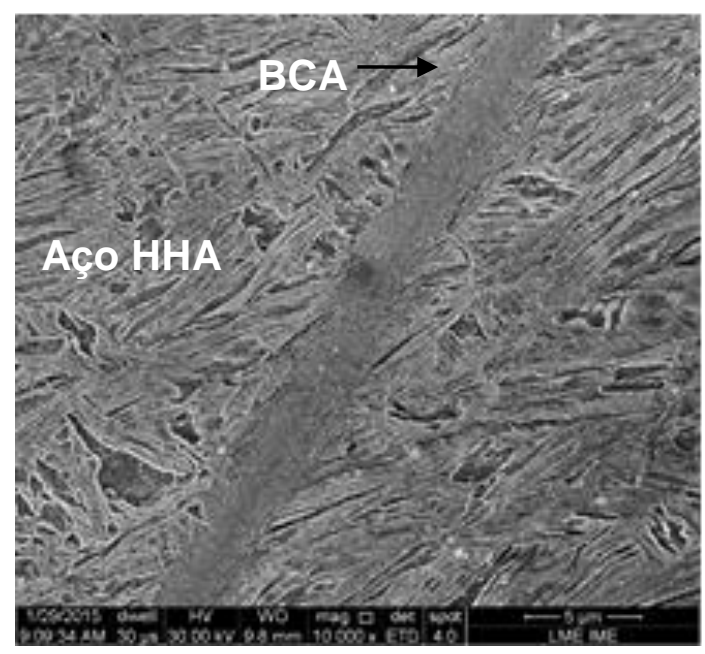

Figura 4. Fotomicrografia de uma banda de cisalhamento adiabático.

A Figura 5 apresenta o processo de nucleação e propagação de trincas no interior de uma banda de cisalhamento. Pode-se observar na Figura 5a, pequenos vazios nucleados na banda de cisalhamento. Estes vazios quando coalescem produzem a trinca, que pode ou não se propagar como apresentado na Figura $5 b$.

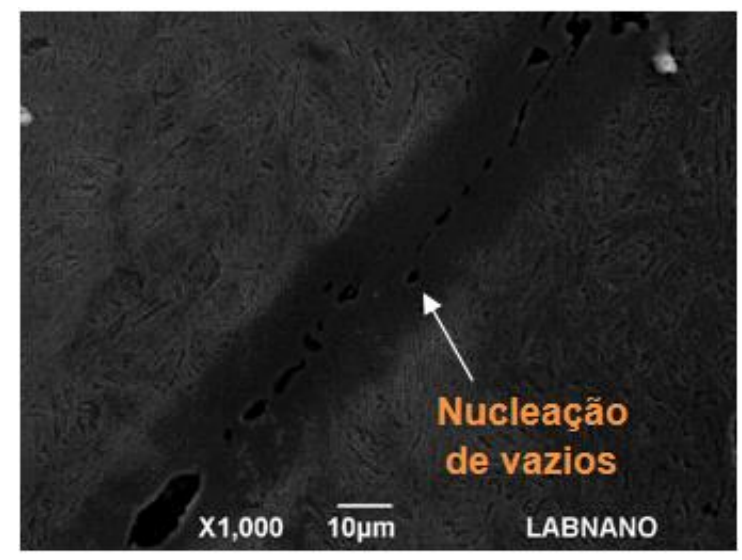

(a)

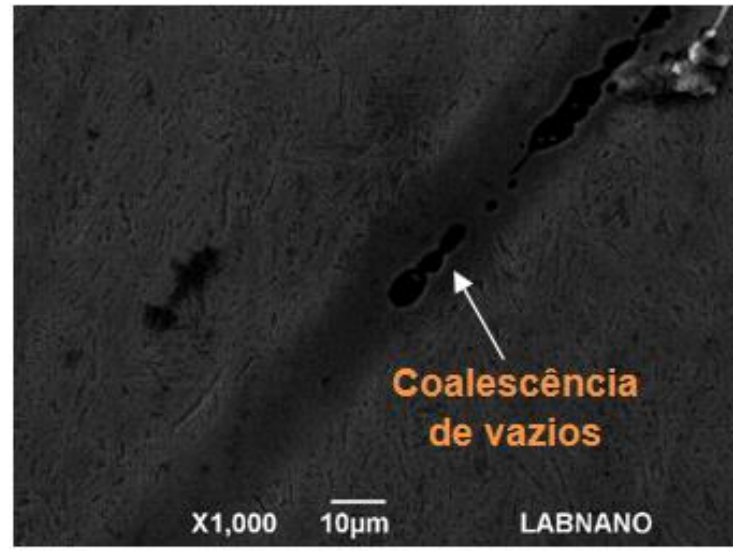

(b) 


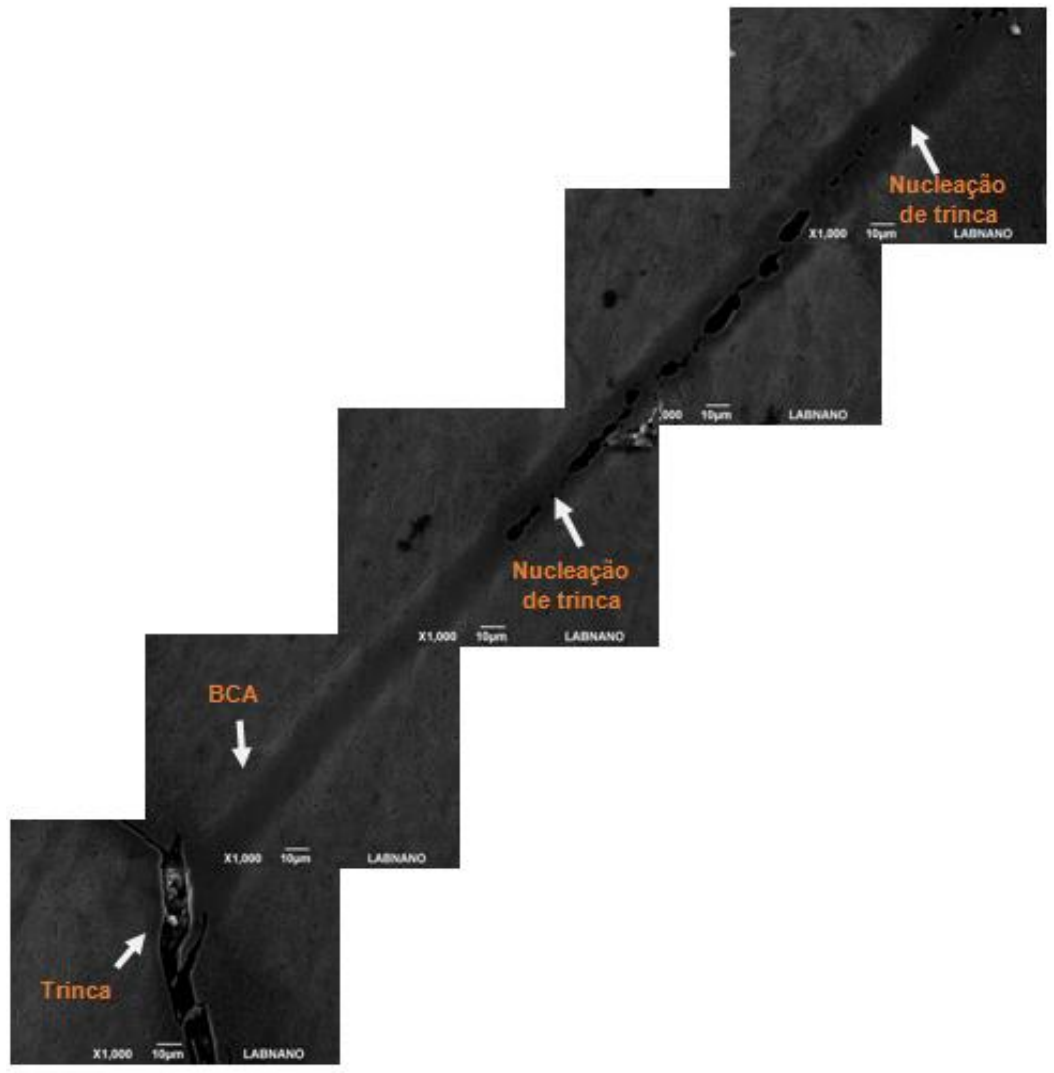

(C)

Figura 5. Fotomicrografia de uma nucleação e propagação de trinca no interior da banda de cisalhamento. Em (a) tem-se a nucleação de vazios, em (b) a coalescência dos vazios em (c) tem-se a banda completa com a trinca.

A Figura 6 apresenta uma BCA proveniente de ondas superficiais compressivas que se dispersaram na superfície da chapa [5]. Observa-se, novamente, a presença de nucleação e propagação de trincas no interior desta banda.

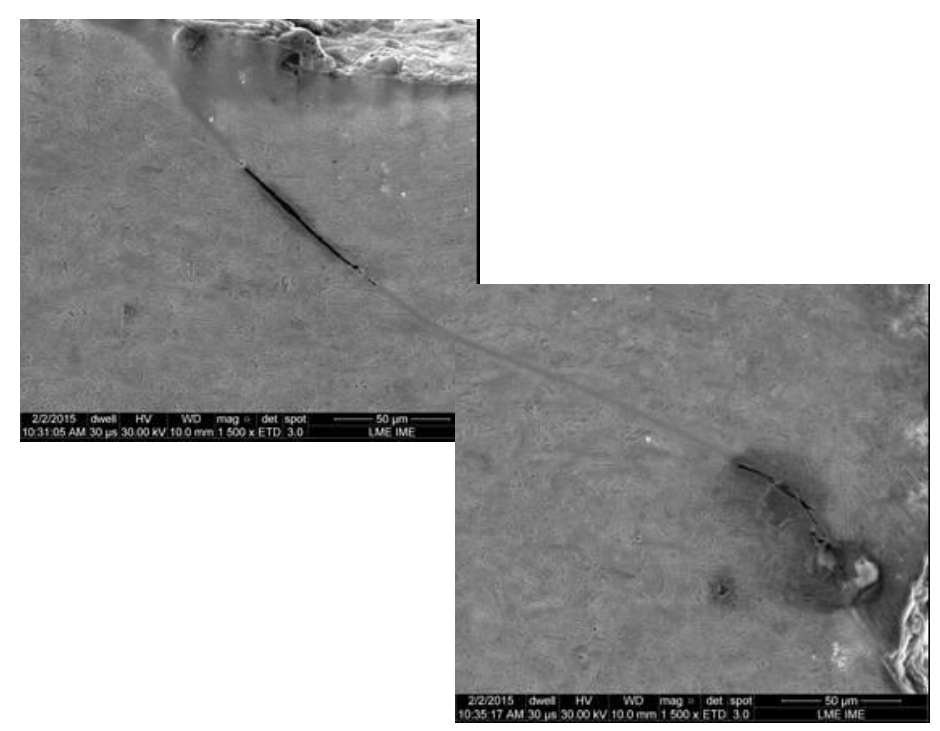

Figura 6. Banda de Cisalhamento proveniente de ondas superficiais. 
A Figura 7 apresenta uma BCA com ramificações produzidas pelo impacto balístico [10].

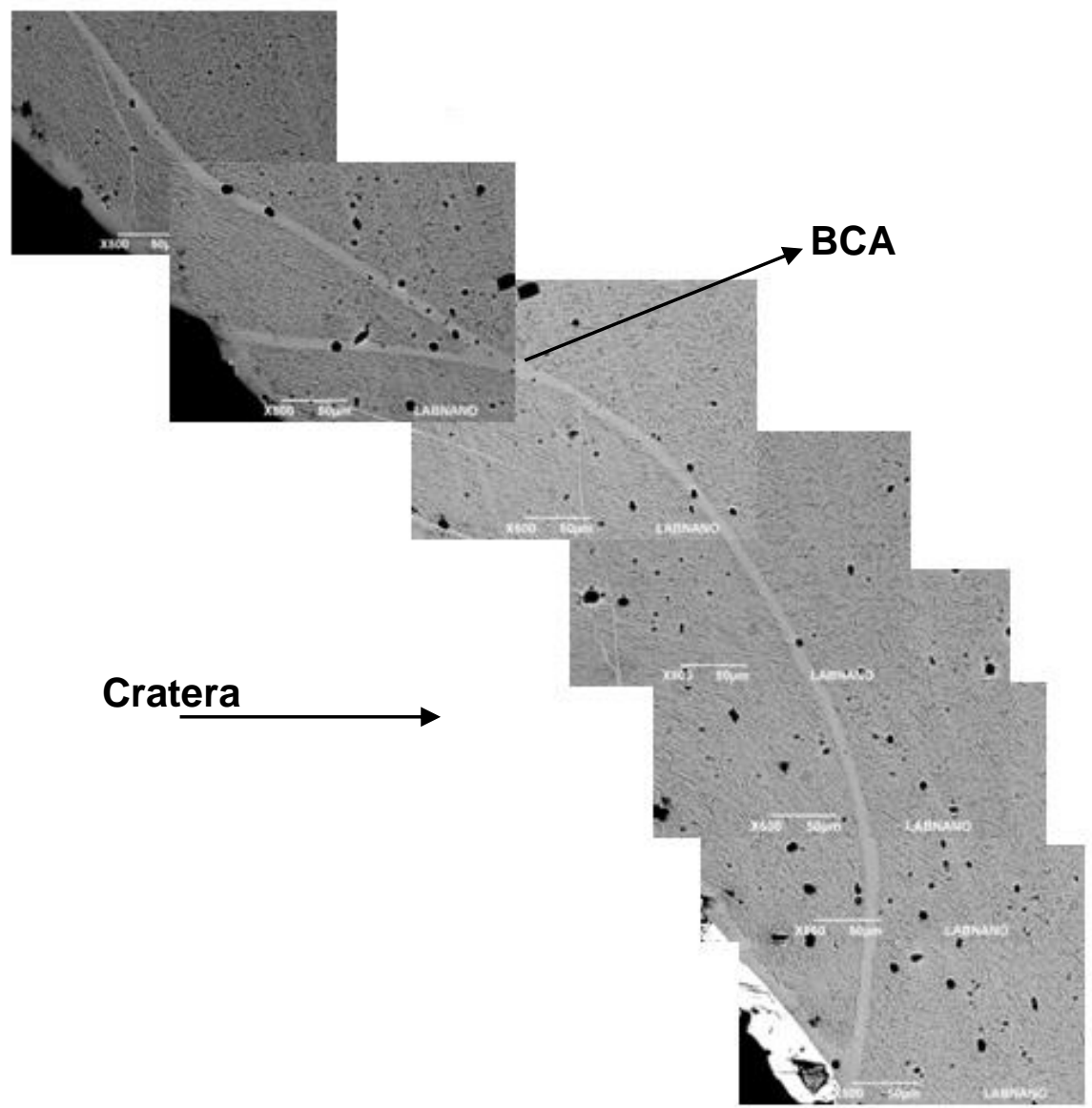

Figura 7. BCA com ramificações.

\section{CONCLUSÃo}

Pode-se concluir, pela análise por microscopia eletrônica de varredura das regiões adjacentes ao impacto balístico, o aparecimento de bandas de cisalhamento adiabático provenientes das altas taxas de deformação produzidas pelo projétil. Os resultados mostram que algumas bandas possuem nucleação e propagação de trincas em seu interior, bem como ramificações dessas bandas.

O motivo do surgimento de trincas no interior da banda não foi escopo deste trabalho, sendo, porém um importante tópico a ser pesquisado.

\section{Agradecimentos}

Os autores agradecem ao Exército brasileiro e ao CNPq, CAPES e FAPERJ, por patrocinar esta pesquisa,bem como, o laboratório de Microscopia eletrônica do IME e o LABNANO no CBPF. 


\section{REFERÊNCIAS}

1 Miguez Suarez, JC. Defesa Anticarro, Rev. Militar de Ciência e Tecnologia, 6 (2) (1989) 51-62.

2 Hazell, PJ. The development of Armour Materials, Military Technology - MILTECH, (4) 2006 54-62.

3 Papetti, DJ. Metallic armor materials. In: Ballistic materials and penetration mechanics, R.C. Laible (Ed). Amsterdam: Elsevier Scientific Publishing Co.,1980. Chapter 7, p.14816.

4 Souza, Elson Renato Santos. Estudo do comportamento microestrutural e balístico de um aço de blindagem após soldagem. 2014. 184p. Dissertação (Mestrado em Ciência dos Materiais) - Instituto Militar de Engenharia, 2014.

5 Oliveira, Suzane de Sant'ana. Estudos dos efeitos terminais em um aço de alta dureza após o impacto balístico, 2015. 166p. Dissertação (Mestrado em Ciência dos Materiais) - Instituto Militar de Engenharia, 2015.

6 Shahkarami, A, Cepus, E, Vaziri, R, Poursartip, A. Material responses to ballistic impact. In: Lightweight ballistic composites - Military and low enforcement applications.A. Bhatnagar (Ed.). Boca Raton: CRC Press, 2006, Chapter 3, p.72-100.

7 Rinker, Robert A. Understanding Firearm Ballistics: Basic to Advance Ballistics Simplified, Illustrated and Explained, 6th edition, Mulberry House Publishing, U.S.A., 2007.

8 Meyers, MA, Dynamic Behavior of Material. New York: John Whiley \& Sons, 1994

9 Zhang, B, Shen, W, Liu, Y, Zhang, R, Some Factors influencing adiabatic shear banding in impact wear. Wear 214 (1998), p.259-263

10 Odeshi, AG, Bassim, MN, Bolduc, M, Damage mechanism in high hardness armor (HHA) steel subjected o V50 ballistic impact, DYMAT 2009, p.563-567

11 Boakye-Yiadom, S, Abdul Khaliq Khan, NabilL Bassim, A Systematic Study of grain refinement during impact of 4340 steel, Elsevier, Canadá, 19 march2014, Materials Science \& Engineering A 605, p. 270-285

12 United state department of army. Norma MIL-DTL-46100E (MR),Amendment 1, Detail Specification Armor Plate, Steel, Wrought, High Hardness, 2008

13 Sthiffer tecnologia LTDA e Fundação Ricardo Franco (FRF), Relatório Técnico do Contrato № TP 24/2008, Resultados finais de ensaios de aços de composições experimentais VCB3Ti e VCB3Ti-MD, Rio de Janeiro, RJ, 2008

14 United state department of National Institute of Justice (NIJ). Norma Standard 0108.01, Ballistic resistant protective materials, 1985. 